\title{
Thermal-Mechanical Modeling and Experimental Validation of Weld Solidification Cracking in 6061-T6 Aluminum
}

\author{
CONF-970369-
}

\author{
J. J. Dike, J. A. Brooks, D. J. Bammann, M. Li \\ Sandia National Laboratories \\ Livermore, California
}

\begin{abstract}
Finite element simulations using an internal state variable constitutive model coupled with a void growth and damage model are used to study weld solidification cracking of 6061-T6 aluminum. Calculated results are compared with data from an experimental program determining the locations of failure as a function of weld process parameters and specimen geometry. Two types of weld solidification cracking specimen were studied. One specimen, in which cracking did not occur, was used to evaluate finite element simulations of the thermal response and calculations of average strain across the weld. The other specimen type was used to determine the location of crack initiation as a function of weld process parameters. This information was used to evaluate the finite element simulations of weld solidification cracking. A solidification model which includes dendrite tip and eutectic undercooling was used in both thermal and mechanical finite element analyses. A strain rate and temperature history dependent constitutive model is coupled with a ductile void growth damage model in the mechanical analyses. Stresses near the weld pool are examined to explain results obtained in the finite element analyses and correlated with experimental observations. Good agreement is obtained between simulation and experiment for locations of crack initiation and extent of cracking. Some effects of uncertainties in material parameters are discussed.
\end{abstract}

\section{Introduction}

Weld solidification cracking occurs during the final stages of solidification. The load histories required to cause cracking can vary greatly depending on the material and the processing conditions. Cracks usually appear to initiate in the solid + liquid region of the weld, although the initiation point may occur near a local solidus temperature significantly lower than the equilibrium solidus. As solidification cracking is one of the most serious weld related manufacturing defects, it has been studied experimentally for more than 50 years [e.g. 1-3]. Many numerical simulations of the stresses, strains, and distortions in welded plates have been reported over the last 20 years. However, only recently have numerical simulations aiming to predict and understand solidification cracking been attempted [4-9]. The metallurgical and thermomechanical aspects of the solidification

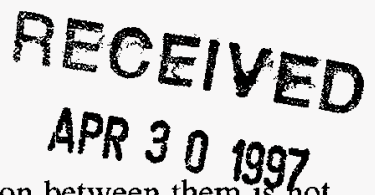

cracking problem and the interaction between them is hot yet well understood. Factors that influ $\Omega$ gracking behavior of a particular part include alloy compostion, boundary conditions, and welding conditions such as the rate of energy input to the part, welding speed, and weld process.

A large number of weldability tests have been developed [10]. Many of these use an externally applied strain to characterize the relative weldabilities of materials. For some materials which are especially prone to solidification cracking, such as 6061-T6 Al, the augmented strains are very close to zero as measured by tests such as the Varestraint test [11]. Other tests, such as the Sigmajig test [12], apply a prestress to the specimen. Cracking susceptibility is measured as the external load required to cause cracking for a given set of weld conditions. Again, different tests tend to rank materials' cracking susceptibility differently. In addition, many of the tests do not represent conditions actually encountered in manufacturing. Even those tests that are termed representative do not necessarily simulate conditions that might be encountered in the range of manufacturing situations of interest. For this reason it is of considerable interest to develop a simulation methodology that may be used in predicting the cracking susceptibility of a particular weld.

\section{Experiments}

Two types of specimens were studied. Rectangular plates $76.2 \mathrm{~mm} \times 152.4 \mathrm{~mm} \times 6.35 \mathrm{~mm}$ ( 3 in $\times 6$ in $\times 0.25$ in) were used to verify thermal and mechanical analyses on crack-free welds. A $127 \mathrm{~mm}$ (5 in) x $25.4 \mathrm{~mm}$ (1 in) groove was milled in the center of the specimen to leave a $1.27 \mathrm{~mm}$ $(0.050$ in) thick web where the weld was placed. The GTA process was used with process parameters of $17 \mathrm{~V}, 55$ or 70 $\mathrm{A}$, and $12.7 \mathrm{~mm} / \mathrm{s}(30 \mathrm{in} / \mathrm{min})$ torch travel speed. Figure 1 shows a schematic of the specimen and the instrumentation. Arrays of thermocouples were placed across the bottom side of the weld at various locations along the weld length. Two arrays of lines with $1.27 \mathrm{~mm}$ (0.050 in) spacing were also scribed on the bottom side of the specimen. These grids were monitored with video cameras to provide strain histories across the weld.

Figure 2 shows the disk specimen used to study crack initiation. These specimens were not instrumented. Weld process parameters were varied and the location of crack 


\section{DISCLAIMER}

This report was prepared as an account of work sponsored by an agency of the United States Government. Neither the United States Goverament nor any agency thereof, nor any of their employees, makes any warranty, express or implied, or assumes any legal liability or responsibility for the accuracy, corrpieteness, or usefulness of any information, apparatus, product, or process disciosed, or represents that its use would not infringe privately owned rights. Reference berein to any specific commereial produch, process, or service by trade name, tradernart manufacturer, or otherwise does not necesearily constitute or impiy its endorsement, recommendation, or favoring by the United States Goverameat or any agency thereof. The views and opinions of authors expressed herein do aot aecessarily state or reflect those of the. United States Government or any agency thereof. 


\section{DISCLAIMER}

Portions of this document may be illegible in electronic image products. Images are produced from the best available original document. 
initiation was observed. The disks were $6.35 \mathrm{~mm}$ thick with the weld placed on the center of the $12.7 \mathrm{~mm}$ wide groove. The web thickness in the groove was $1.27 \mathrm{~mm}$. Specimen outside diameter was $101.6 \mathrm{~mm}$. A $6.35 \mathrm{~mm}$ hole was used to mount the specimen to a fixture. In the tests, three current levels were used for each circular weld. Four disk tests will be discussed and are listed in Table 1. All tests used a voltage of $17 \mathrm{~V}$.

\begin{tabular}{|c|ccc|c|}
\hline \multirow{2}{*}{ Test } & \multicolumn{2}{|c|}{ current $(\mathrm{A})$} & $\begin{array}{c}\text { trave } \\
\text { speed }(\mathrm{mm} / \mathrm{s})\end{array}$ \\
\cline { 2 - 5 } & \multicolumn{2}{|c|}{$\begin{array}{r}\text { position around disk } \\
0-120^{\circ}\end{array}$} & \\
\hline & $50-240^{\circ}$ & $240-360^{\circ}$ & \\
\hline 1 & 50 & 55 & 60 & 6.35 \\
2 & 30 & 40 & 50 & 6.35 \\
3 & 60 & 70 & 80 & 10.7 \\
4 & 40 & 50 & 60 & 10.7 \\
\hline
\end{tabular}

Table 1. Weld process parameters for disk tests.

The location of through-thickness crack initiation was the quantity of interest for comparison with the finite element analyses. Figure 3 shows how cracks typically initiated on the outer edge of the weld fusion zone and ran to the

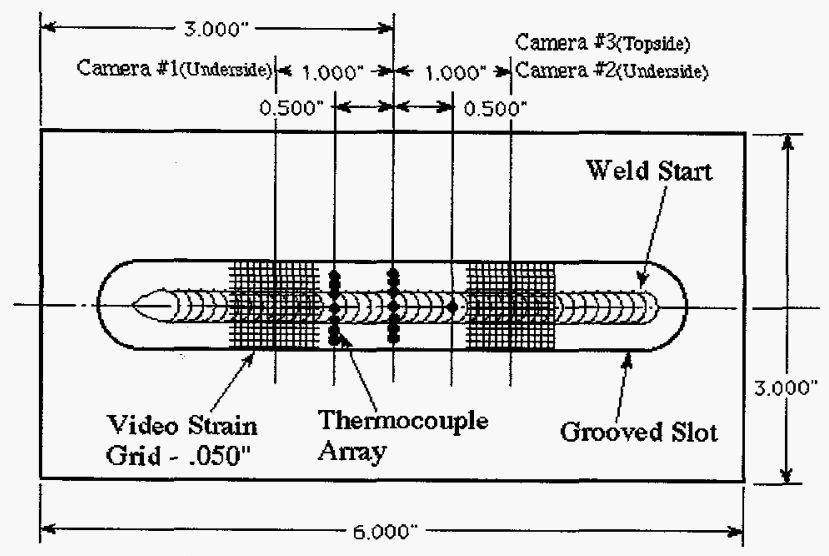

Figure 1. Schematic of rectangular specimen and instrumentation. Dimensions in inches.

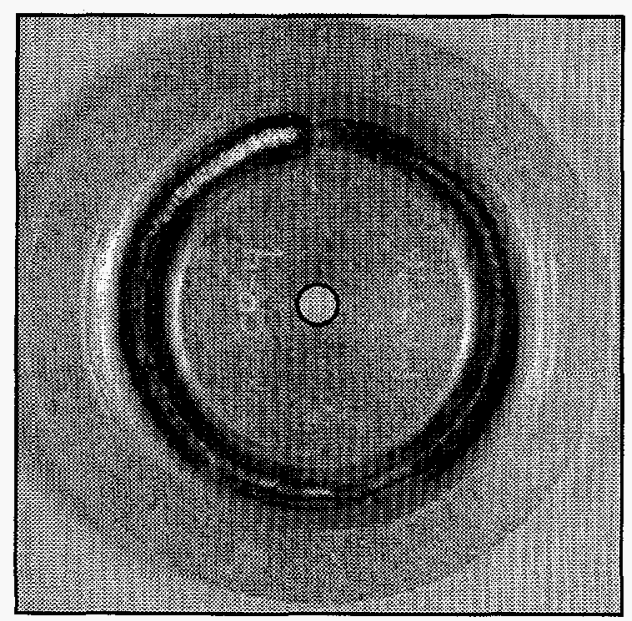

Figure 2. Top view of disk specimen used to study crack initiation. centerline where they continued to propagate. Table 2 lists the locations at which cracks initiated for each test.

\begin{tabular}{|c|c|}
\hline Test & $\begin{array}{c}\text { crack initiation } \\
\text { (distance from weld start) }\end{array}$ \\
\hline 1 & $0^{\circ}$ \\
2 & $190^{\circ}$ \\
3 & $0^{\circ}$ \\
4 & $160^{\circ}$ \\
\hline
\end{tabular}

Table 2. Locations at which through-thickness cracks initiate.

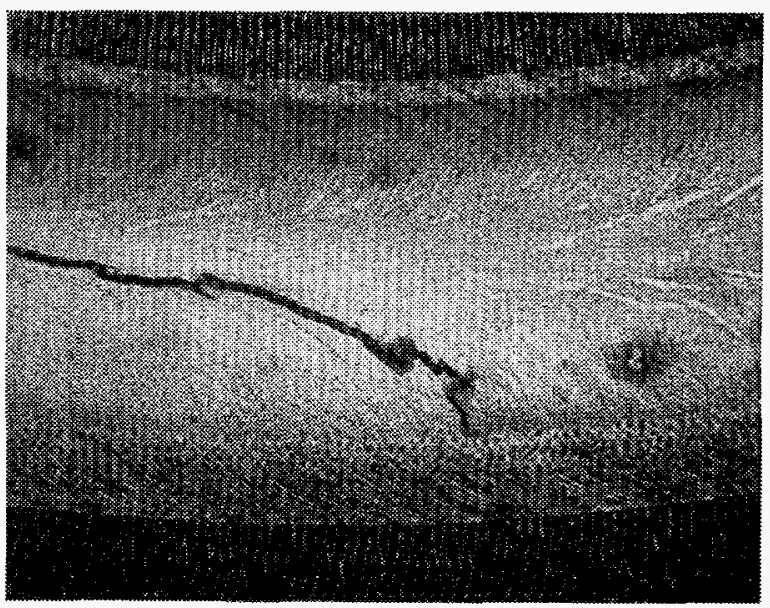

Figure 3. Photo showing crack initiating from outside edge of weld fusion zone.

\section{Thermal Finite Element Analyses}

In order to capture some aspects of the solidification behavior, a solidification model incorporating both dendrite tip and eutectic undercooling was used. The determination of the fraction solidified as a function of temperature and weld speed is described in [13]. Briefly, a pseudo Al-Si phase diagram was constructed based on Al-Si binary and Al-Mg-Si ternary phase diagrams. This estimated phase diagram was used to determine undercooling effects for the weld process parameters of interest.

Figure 4 shows the resulting fraction solid curve as a function of temperature for $6.35 \mathrm{~mm} / \mathrm{s}$ weld speed. Undercooling of approximately $6^{\circ} \mathrm{K}$ is calculated for a $12.7 \mathrm{~mm} /$ $s$ weld speed.

The Sandia code JACQ3D [14] was used to perform the analyses. Thermal properties were obtained from the High Temperature Materials Information Analysis Center [15]. The specific heat curve was modified to represent the rate of solidification shown in Fig. 4. Figure 4 shows that the material is nearly $60 \%$ solidified within a few degrees of the liquidus temperature. Distributing the latent heat of fusion according to the fraction solid curve in Fig. 4 results in a very nonlinear specific heat curve, shown in Figure 5. Figure 5 shows a spike at the eutectic temperature (approximately $828^{\circ} \mathrm{K}$ ) and a large spike near the liquidus temperature at $920-930^{\circ} \mathrm{K}$. The flat region at the liquidus shows the temperature region over which the solidification at the 


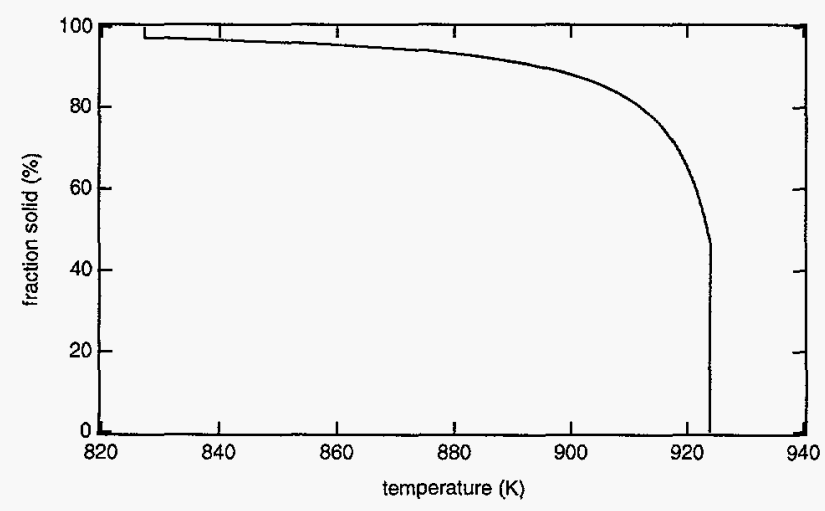

Figure 4. Fraction solid as a function of temperature for 6061-T6 Al, $6.35 \mathrm{~mm} / \mathrm{s}$ (15 ipm) travel speed.

liquidus temperature was distributed to avoid numerical difficulties. Feng [4] and Dike et al [8] showed how different solidification models could affect isotherm shapes near the weld pool. Specifically, it was shown that isotherms are more elongated near the tail of the pool in the solidification temperature range when these solidification models areused compared to assuming a uniform solidification rate. As the weld pool is surrounded by a compressive stress and followed by tensile transverse stress, factors that causes the weld pool to become elongated may increase the chance of solidification cracking. The susceptible material may be pushed closer to the trailing tensile region.

Figure 5 also shows the thermal conductivity increasing by roughly a factor of 4 at the liquidus temperature. The conductivity is modified in this manner to account for enhanced convection that occurs in the weld pool due to stirring and digging of the welding arc. The multiplication factor is based on studies of fluid mechanics and heat transfer in the weld pool [16].

Energy was input to the thermal model using a double

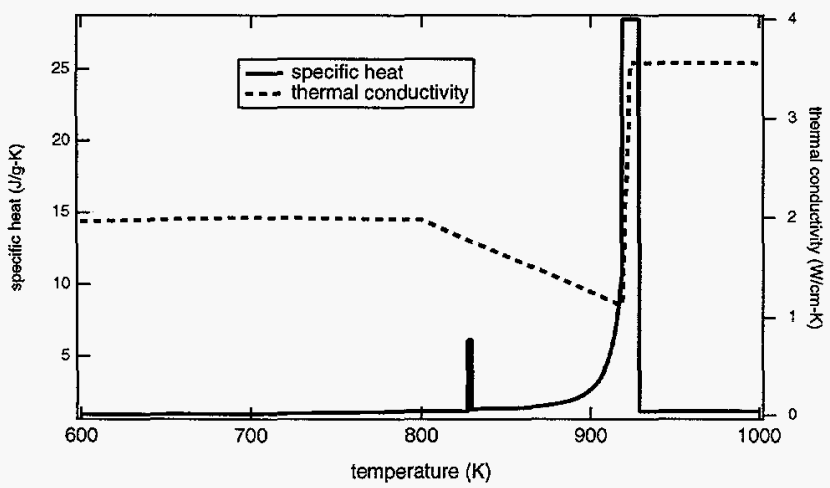

Figure 5. Specific heat and thermal conductivity curves used in thermal analyses.

ellipsoidal volumetric heat source [17]. Heat source efficiency was assumed to be $75 \%$. Thermal losses were accounted for by radiative and free convection heat transfer being combined into a temperature dependent effective convective heat transfer coefficient.

Figure 6 shows the mesh used for the rectangular specimen. It is constructed of approximately 32,000 8-node hex elements. Typically the mesh was constructed to have several elements across the width and length of the weld pool.

A representative comparison of temperature histories from analysis and experiment for the rectangular specimen is shown in Figure 7. Thermocouple locations on one side of the weld are indicated by solid symbols, thermocouples on the opposite side by open symbols. Calculated temperatures are indicated by solid lines. The data shows that the thermocouples did not end up being equally spaced away from the weld centerline. The analysis curves are at the nominal locations specified in the thermocouple schematic,

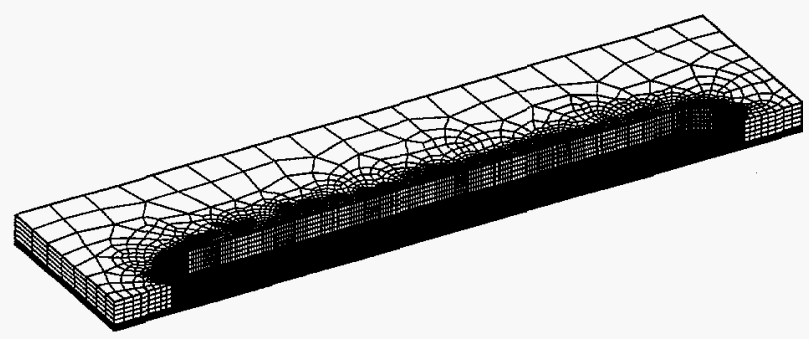

Figure 6. Mesh used in finite element analyses of rectangular specimen.

Figure 1. The results in Figure 7 indicate that the analysis compares well with the test, as the calculated temperature histories fall between the experimental curves. There is a difference in the curve shape at the location closest to the weld centerline. The analysis curve is significantly wider than the thermocouple history from the peak temperature of approximately $1100 \mathrm{~K}$ (liquidus temperature is approximately $920^{\circ} \mathrm{K}$ ) to $600^{\circ} \mathrm{K}$. There was only one thermocouple that survived at this location, so it is not clear how much scatter there is in the data at this location. The peak temperatures do agree well. There are still many details that could be improved to match analysis to experimental thermal data, but overall, the thermal analyses were sufficiently accurate to proceed to the mechanical analyses.

\section{Mechanical Finite Element Analyses}

A strain rate and temperature history dependent internal state variable constitutive model [18-21] was used in the mechanical analyses. A nonlinear least squares package specifically designed to fit parameters to the model [22] was used to generate a parameter set based on data generated for this work [23]. A representative comparison of the constitutive model's predicted response with experimental data for a strain rate of $0.2 \mathrm{~s}^{-1}$ is shown in Figure 8. The

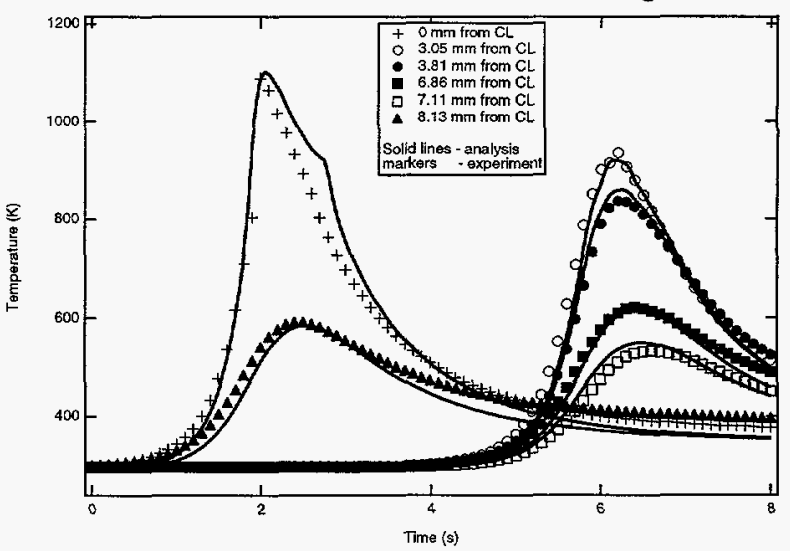

Figure 7. Comparison of temperatures from experiment and analysis. Rectangular plate, $17 \mathrm{~V}, 55 \mathrm{~A}$, $12.7 \mathrm{~mm} / \mathrm{s}$. 
yield stress and elastic constants as a function of temperature are shown in Figure 9.

The elastic modulus was determined by calculating the slopes from elevated temperature compression test data from [23] and assuming a hyperbolic tangent form for the temperature dependence. This results in a very small modulus at melt. Other measurements of elastic constants [24] indicate the modulus decreases linearly to approximately $50 \%$ of its room temperature value at melt. It was not clear which is the most appropriate behavior to assume with regards to the finite element model and the fit to the constitutive model. Various assumptions for the temperature dependence of Young's modulus, Poisson's ratio, and thermal linear expansion were examined. Results will be presented using the temperature dependencies shown in Figure 9. Thermal linear expansion was assumed to increase nearly linearly from room temperature with the expansion due to the liquid-solid phase transition included.

The damage model is based on the Cocks-Ashby model of growth of a spherical void in a rate dependent plastic material [25]. The effects of damage due to the growth of an initial distribution of voids or initial porosity is modeled by the introduction of a scalar internal state variable $\phi$. The variable acts to degrade the elastic moduli and concentrate the stress in the deviatoric flow rule. When damage reaches a critical value, failure occurs.

The evolution of the damage parameter $\phi$ is given by

$$
\dot{\phi}=\beta\left[\frac{1}{(1-\phi)^{\mathrm{n}}}-(1-\phi)\right]|\mathrm{D} \mathrm{p}|
$$

where $|D|$ is the magnitude of the deviatoric plastic stretch.

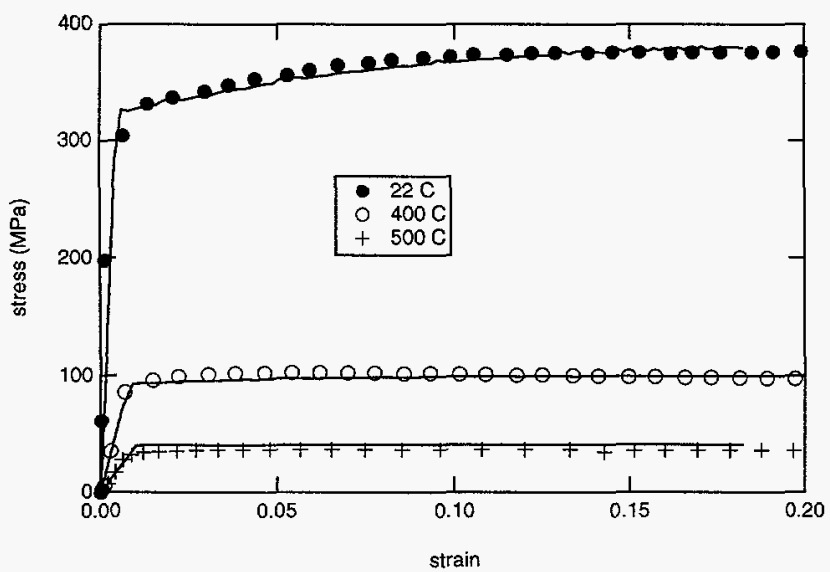

Figure 8. Representative comparison of constitutive model response compared with experiment.

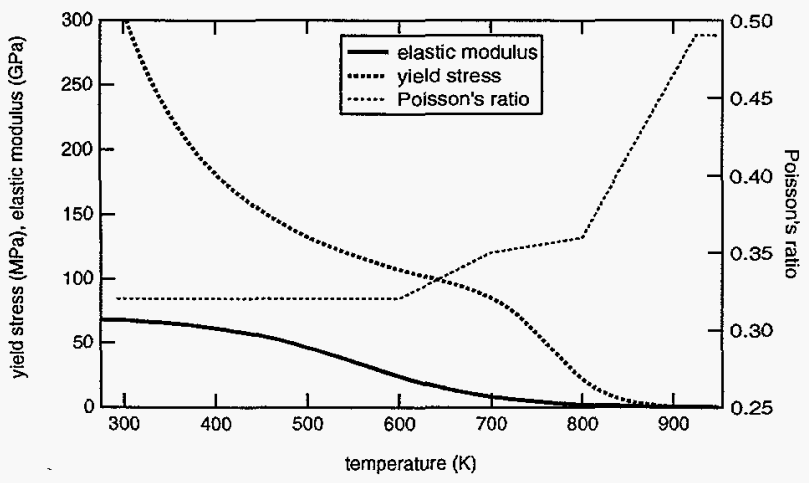

Figure 9. Elastic constants and yield stress used in mechanical analyses.
The term $\beta$ is a measure of the triaxiality (pressure/effective stress). The exponent $n$ in (1) controls the rate at which voids grow for a given level of stress triaxiality. Tests were conducted to obtain a rough estimate of how the damage exponent $n$ varies with temperature [23]. Notched tensile specimens with different ratios of the notch radius to the minimum specimen diameter were used to introduce various levels of triaxiality into the gage section of the specimen. Trial and error finite element analyses were used to determine the damage exponent once parameters for the plasticity model have been determined from compression tests.

The temperature dependence of the damage exponent $n$, as estimated through trial and error finite element analyses of the elevated temperature notched tensile specimens, is described by Eqn. 2. Using data from three temperatures $\left(293^{\circ} \mathrm{K}, 593^{\circ} \mathrm{K}, 693^{\circ} \mathrm{K}\right)$ and an estimated saturation level, a hyperbolic tangent shape is assumed for $\mathrm{n}$ as a function of temperature as

$$
\mathrm{n}(\mathrm{T})=\mathrm{n}_{\mathrm{S}}+\left(\mathrm{n}_{\mathrm{O}}-\mathrm{n}_{\mathrm{S}}\right)\left\{1+\tanh \left[\left(\mathrm{C}_{1}-\mathrm{T}\right) / \mathrm{C}_{2}\right]\right\} / 2,
$$

where $\mathrm{T}$ is temperature, $\mathrm{n}_{0}=5.8$ is the room temperature value, $n_{s}=0.6$ is the saturation value, and $C_{1}=625^{\circ} \mathrm{K}$ and $\mathrm{C}_{2}=61^{\circ} \mathrm{K}$ are constants fit to the data. The saturation value is the value to which the function tends at melt. From extensive data in the literature it is known that cracks do not initiate in the weld pool itself, but rather during the later stages of solidification or very soon after solidification is completed. Figure 10 shows a crack surface in the region of the initiation site. It is evident from the second phase eutectic constituents and the smooth dendrite surfaces that crack initiation occured during the final stages of eutectic solidification.

The constitutive model subroutine was modified such that damage increased only in elements that were below the coherent temperature. The coherent temperature was determined from the solidification model as the temperature at which the material was $75 \%$ solidified. This is approximately when the material is able to carry a tensile load due to the dendrites forming an interconnecting network [26,27]. In addition, if the element temperature was above the solidus temperature, damage was only allowed to increase if the element was resolidifying - this prevented material failing as it melted.

Time steps were selected such that several steps were taken during the solidification temperature range. This choice resulted in time steps of approximately $0.035 \mathrm{~s}$. When strains averaged across the weld were the item of interest, larger time steps $(\sim 0.2 \mathrm{~s})$ could be taken without significantly altering the predicted average strain across the weld. The finite element code JAS3D $[14,35]$ was used with a dynamic relaxation solver to perform the analyses.

The rectangular specimens were used to validate temperatures and strains calculated in the analyses. Figure 11 shows strain history comparisons for two rectangular plates that did not crack. Two current levels were used and strains were measured at different locations. The locations are shown by the video strain grids in Fig. 1. Gage length was approximately $6.35 \mathrm{~mm}$. The curves show the change in grid point separation relative to the initial $6.35 \mathrm{~mm}$ span across the weld as a function of time. The $55 \mathrm{~A}$ test with 


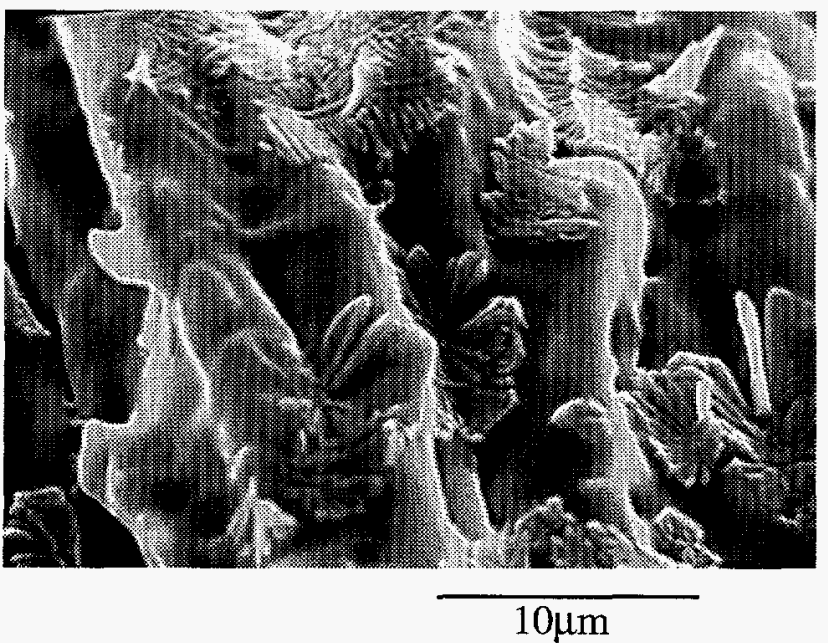

Figure 10. Fractograph of solidification crack surface in 6061-T6.

strains recorded 2 in $(50.8 \mathrm{~mm})$ from the starting edge of the plate shows the grids initially becoming farther apart before the weld pool reaches the measurement location. The strain becomes negative before the weld pool reaches the 2 in measurement location due to shrinkage of the weld. A similar response is observed for the $70 \mathrm{~A}$ test 4 in from the starting edge of the plate, except no initial expansion is observed in the calculated strain. The expansion shown in the experimental data at the 4 in location is within the uncertainty of the video measurement technique $(0.2 \%)$. The welding torch arrives at the 2 in and 4 in locations at approximately $2.5 \mathrm{~s}$ and $6.5 \mathrm{~s}$, respectively.

Previous work focused on the Houldcroft specimen $[5,8]$. It was not used for validating cracking calculations because it is more a test of crack extension rather than crack initiation. It was felt that finite element predictions of crack initiation are more reliable than predictions of crack extent, and crack initiation is of more interest at this time. Therefore a test in which location of crack initiation varied with process parameters was sought. The circular patch test, described in the Experiment section, was found to be useful for studying crack initiation. Several finite element models of the specimen were generated, with a representative model presented in Figure 12. It was constructed of approximately 85008 -node hex elements. To reduce the number of elements in some models, the central hub was connected to the

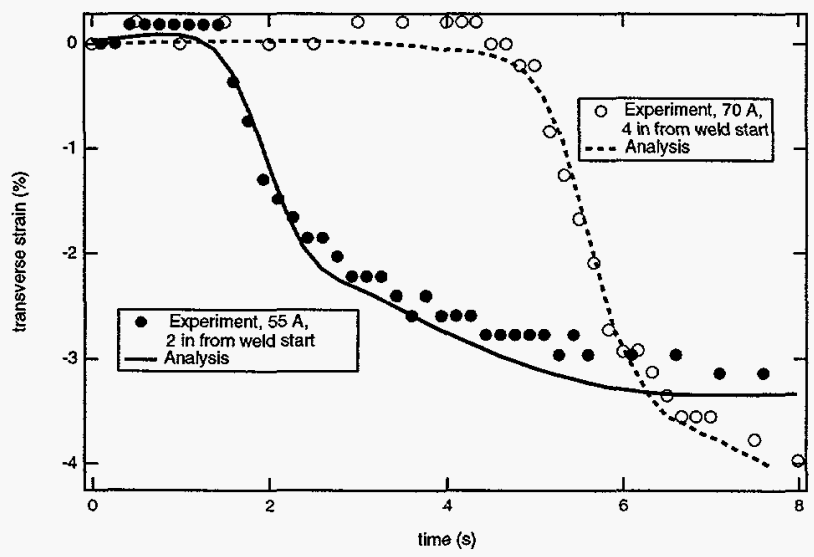

Figure 11. Comparison of calculated and measured strains for two rectangular specimen tests. outer ring of elements using contact surfaces. Two elements were used through the web thickness. The disk appeared to remain flat during the experiment and the majority of welds were full penetration with fusion zone boundaries perpendicular to the web surface.

\section{Calculations of Solidification Cracking}

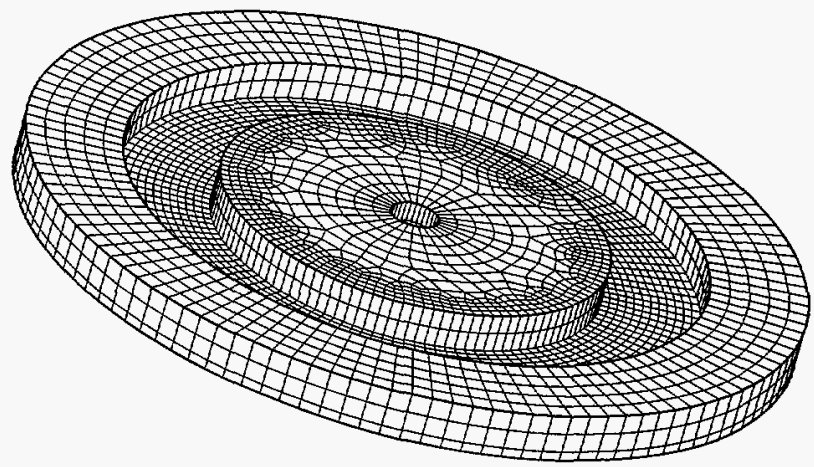

Figure 12. Example of finite element mesh used in crack initiation simulations.

In the context of the constitutive and the void growth and damage models, three requirements must be satisfied simultaneously to cause an element to fail in the solidification region. The first requirement is the hydrostatic pressure must become tensile somewhere in the solidifying material. Without a tensile pressure there is no driving force for void growth. If the hydrostatic pressure is not tensile, $\beta$ in Eqn. 1 is zero, resulting in zero rate of change in damage. The second requirement is that the material be plastically deforming while a tensile pressure exists, since void growth occurs only during plastic deformation in the model. The third requirement is that the level of triaxiality, or the ratio of the pressure over the effective stress $\left(\mathrm{p} / \sigma_{\text {eff }}\right)$, be large enough to drive the void growth to failure. For a given value of $p / \sigma_{\text {eff }}$, the damage exponent in Eqns. 1 and 2 must be large enough to cause damage to increase to the failure level during the time the three requirements above are satisfied. For the case of solidification cracking, these criteria must be satisfied in the solidification temperature range.

Many analyses were performed to study the relationship between stress, temperature, and damage for an experiment in which the crack formed very near the start of the weld. Because the material response near melt is not well characterized, analyses were performed to determine how the choice of elastic constant, damage exponent, and thermal expansion behaviors near melt affected the items listed above.

Figure 13 shows the pressure, von Mises stress, and temperature history for an element near the start of the weld at the weld centerline. It shows the effective stress going very close to zero during the time the material is melted. The effective stress then rises smoothly as the temperature drops below the final solidification temperature The pressure becomes tensile (negative here) near $550^{\circ} \mathrm{K}$, well below the solidus temperature. As the rate of energy input is increased into the part, for instance by increasing the current and keeping other quantities the same, the temperature 
at which the pressure becomes tensile increases. For instance, increasing the current by $35 \%$ causes the temperature at which the pressure at the weld centerline becomes tensile to increase by more than $50^{\circ} \mathrm{K}$. Other factors such as the temperature dependence of the elastic constants and the yield strength influence when the pressure becomes tensile. The tensile pressure crossover temperature (where it becomes tensile during solidification) increases as the elastic modulus is increased. The thermal expansion temperature dependence also influences this tensile pressure crossover. More expansion appears to push the tensile region closer to the weld pool. A similar response is observed when the yield strength is increased in the solidification range. The interaction of these effects still needs to be determined, and it is apparent that to quantitatively predict solidification cracking material properties near melt must be better defined. Also not included in any of the modeling are effects of grain size and microstructure, which are known to influence solidification cracking.

Another experimental observation is that once the cracks started they continued to follow the weld to the end of the test. To understand part of the reason for this, histories of pressure/effective stress were compared for elements on the weld centerline at different positions along the weld. This analysis did not allow cracks to form. Figure 14 shows these histories for elements $0^{\circ}, 90^{\circ}, 180^{\circ}$, and $270^{\circ}$ from the start of the weld. The pressure/effective stress ratios are plotted against temperature for each element to compare when the pressure becomes tensile with respect to the element temperature. Figure 14 shows that the temperature at which the pressure becomes tensile increases as the weld proceeds - indicating that the likelihood of solidification cracking increases at greater distances from the weld start. This is partly due to the overall temperature of the part increasing as the weld progresses and the contraction of all

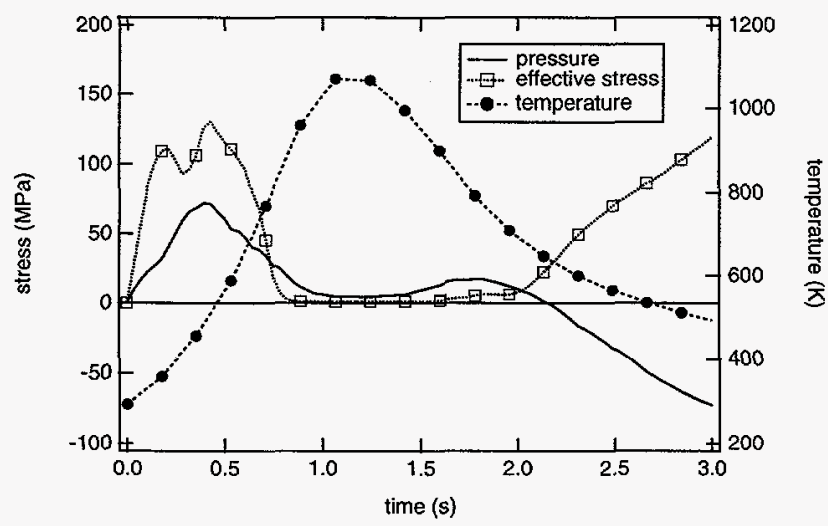

Figure 13. Pressure, effective stress, and temperature as a function of time for an element at weld center.

the elements previously welded. It can also be observed from Figure 14 that the pressure/effective stress is relatively constant for a period after the weld pool passes. It is also of interest to note that the ratio is relatively independent of position around the weld, at least for the modeling assumptions used here. This indicates that the loading does not necessarily increase with distance from the weld, but rather that the tensile loading appears to develop in material more susceptible to cracking as the torch travels around the disk.

It was also observed in the experiment that cracks usu- ally initiated on the edge of the weld farthest from the disk center, as shown in the close-up in Figure 3. The finite element analyses provide some indication of why this may occur. Figure 15 shows pressure/effective stress ratios as a function of temperature for five elements spanning the weld at a location close to the start of the weld. Element $A$ is closest to the center of the disk and is at the inner edge of the weld. Element $\mathrm{E}$ is at the edge of the weld closest to the outer edge of the disk. Elements B, C, and D are equally spaced between $A$ and $E$, with element $C$ being at the weld centerline. Figure 15 shows that with respect to temperature, the pressure becomes tensile first at the inner and outer edges of the weld. This may partially explain why cracks initiate on the outer edge of the weld. The centermost element is loaded by a tensile pressure last. Again all of the locations show about the same level of triaxiality (pressure/

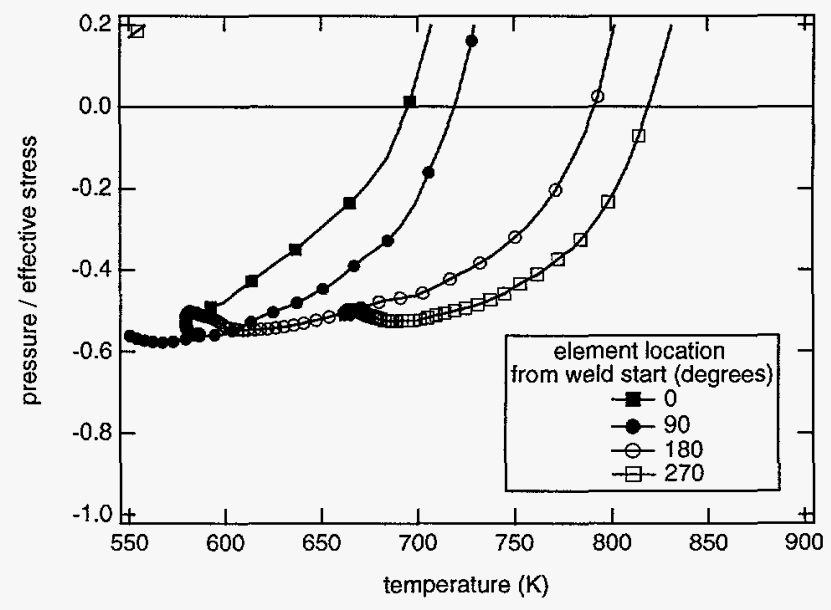

Figure 14. Temperature at which pressure becomes tensile $(<0)$ as a function of distance from weld start for disk specimen.

effective stress). In Figure 15 it appears that the innermost element actually sees tensile loads slightly earlier temperature-wise than the outer element. Figure 16 shows time histories of pressure for the five elements. This figure indicates that the outermost element is subjected to the tensile load earlier in time than the innermost element. This would suggest the outer element should fail first even though the innermost element is loaded in tension at a higher temperature. Failure of the outermost element will relieve some of the load so the inner element would be less likely to fail. This is consistent with the behavior observed in the experiments.

Another indication that the outer edges of the weld are more likely to be crack initiation sites than the center is that the temperature at which the stress drops below the local yield stress occurs last at the outer elements. This would indicate that material is plastically deforming during solidification longer in elements at the weld edge than at the weld center. This is shown in Figure 17. The yield stress is shown to drop from approximately $10 \mathrm{MPa}$ at the nonequilibrium solidus temperature of $828^{\circ} \mathrm{K}$ to approximately $0.6 \mathrm{MPa}$ at the liquidus temperature of $923^{\circ} \mathrm{K}$. Forest and Bercovici [26] and Nedreberg [28] both discuss test data for yield strength near melt indicating yield strengths at the solidus temperature for aluminum alloys on the order of a few $\mathrm{MPa}$. The yield stress drops to zero between $75 \%$ and $85 \%$ frac- 


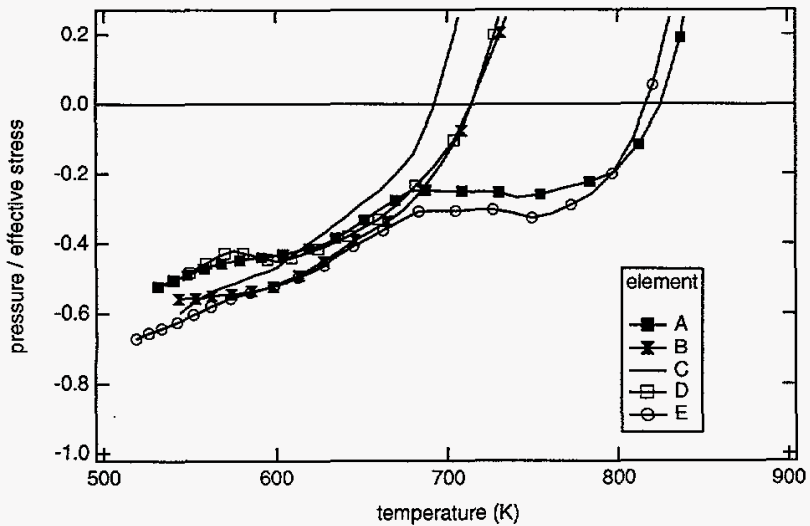

Figure 15. Temperature at which pressure becomes tensile $(<0)$ for elements spanning the weld near weld start for the disk specimen.

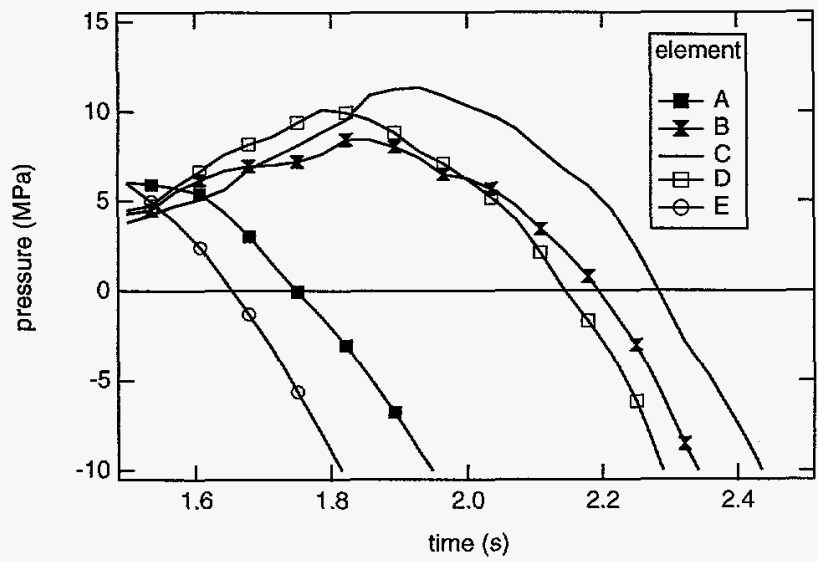

Figure 16. Time histores of pressure for elements spanning weld near weld start.

tion solid in [26]. Figure 17 indicates that effective stress in the center element $C$ in the weld drops below the yield stress near $870{ }^{\circ} \mathrm{K}$ in this example. In the two elements just offcenter, the effective stress drops below yield near $865^{\circ} \mathrm{K}$. Finally, in the elements at the weld edges the effective stress drops below yield near $835^{\circ} \mathrm{K}$. The actual temperatures at which this occurs are probably not well predicted, but the trend appears to be consistent with the experimental observations of crack initiation.

Simulations of the four tests described in Tables 1 and 2 were performed to determine where cracking would initiate. Figure 18 shows predicted cracking for test 1 in which a continuous crack formed near the start of the weld at $\sim 0^{\circ}$. Welding begins at the top of the figure and proceeds clockwise. The dark areas show failed elements which represent cracks. Figure 18 shows some cracking is predicted on both sides of the weld, but more failure occurs on the outside edge of the weld. This is somewhat consistent with the observations of cracks initiating on the outer edge of the weld. Cracking is not predicted to go to the weld centerline, rather it stays on the outer edges of the weld. One explanation for this is that no information is included in the model regarding grain orientation or any directionality or property changes due to the microstructure. In addition, the discretization of the model may not be sufficient to capture

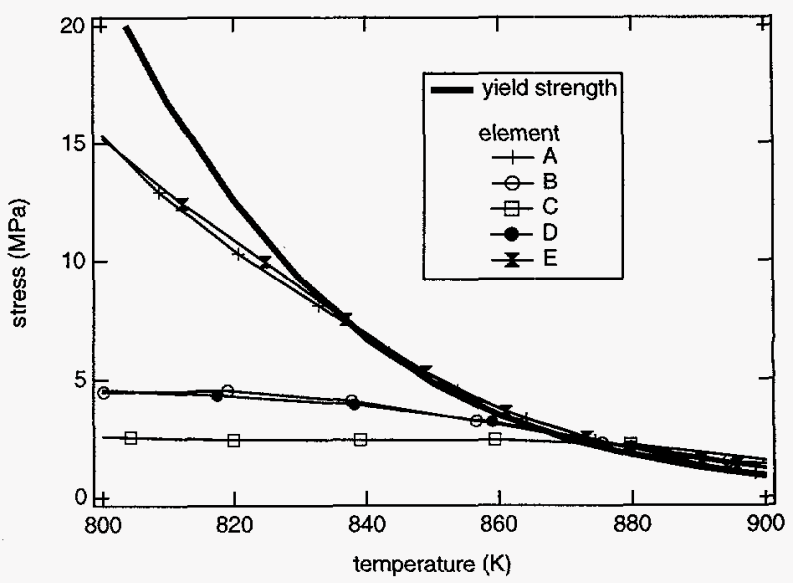

Figure 17. Effective stress as a function of temperature for elements spanning weld near weld start compared to yield stress as a function of temperature.

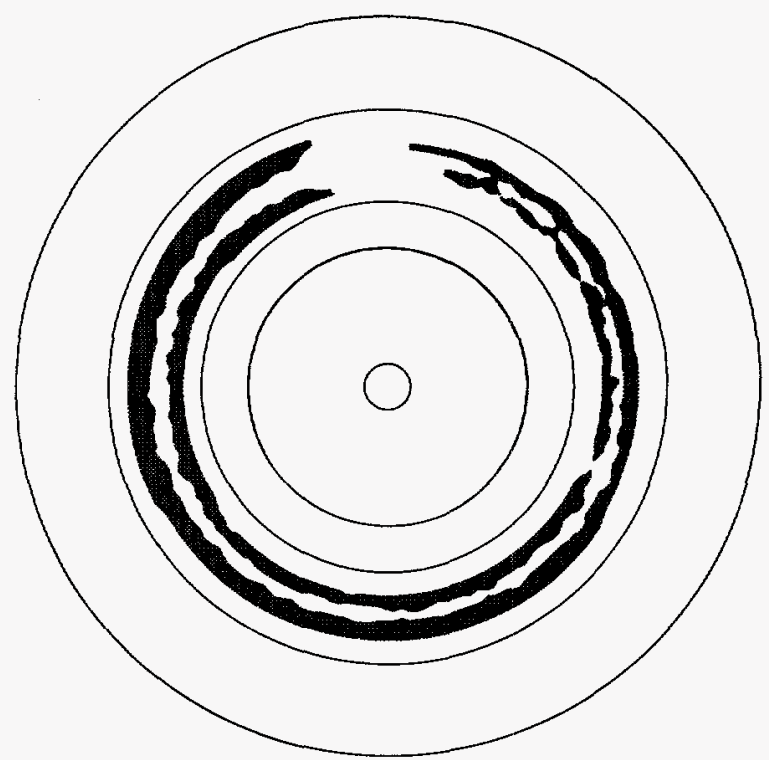

Figure 18. Predicted cracking for test 1 . Welds start at top of disk and proceed clockwise. Dark areas show failed elements.

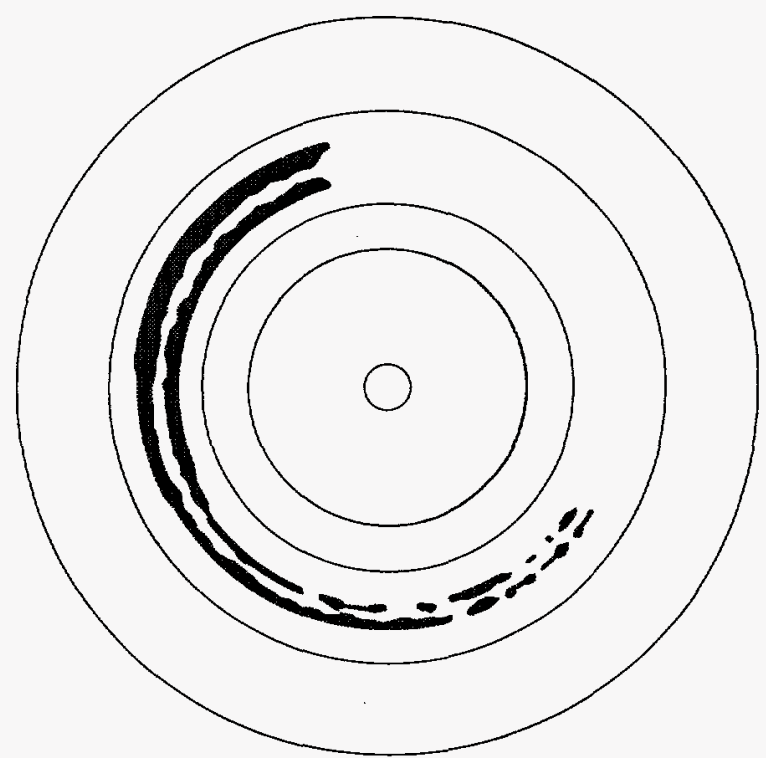

Figure 19. Calculated cracking for test 2, where cracking began near $190^{\circ}$ in the experiment. 
the crack extension correctly. Rather it appears more as a continuous series of initiations. Another observation is the failures are discontinuous at first. This is due partly to the tolerances used in the analyses. Tighter tolerances produce less of the discontinuous failures but essentially reproduce the failure shown in Figs. 18 and 19, though at significantly greater computational expense. It also was observed in experiments on similar geometry specimens in Al-Cu alloys that for some conditions many cracks would initiate but not propagate early in the weld.

The same modeling assumptions and procedures were applied to the other three disk tests. Figure 19 shows calculated cracking for test 2 , in which cracking began at $190^{\circ}$ in the experiment. The analysis shows failure beginning near $130^{\circ}$ with a continuous crack beginning near $165^{\circ}$. Table 3 lists the results for the analyses corresponding to the four disk tests described in Table 2. Failure in the simulations is presented by listing the angles at which a continuous crack forms. Analyses with higher resolution, spatially and perhaps temporally, would provide a more definitive estimate of when cracking initiates using the current damage model. Another consideration in comparing the calculated and experimental results is that a limited number of experiments were performed, so the scatter in the experiments is not known. The main objective was to demonstrate the correct trends, and if the models are calibrated to a test, they do seem to be useful in predicting trends for other process parameter sets and geometries. The same modeling assumptions were used on the rectangular plates in which no damage was observed in the tests. No failure was predicted in the models.

\begin{tabular}{|c|c|c|}
\hline \multirow{3}{*}{ Test } & \multicolumn{2}{|c|}{$\begin{array}{c}\text { location of crack initiation } \\
\text { (distance from weld start) }\end{array}$} \\
\hline & experiment & model \\
\cline { 2 - 3 } 1 & $0^{\circ}$ & $0^{\circ}$ \\
2 & $190^{\circ}$ & $165^{\circ}$ \\
3 & $0^{\circ}$ & $5^{\circ}$ \\
4 & $160^{\circ}$ & $130^{\circ}$ \\
\hline
\end{tabular}

Table 3. Comparison of measured and calculated crack initiation locations for disk tests.

\section{Summary and Conclusions}

A series of experiments and analyses were performed to develop finite element techniques for modeling weld solidification cracking in 6061-T6 aluminum. Conditions for failure in terms of an internal state variable plasticity model coupled with a ductile void growth damage model were discussed with reference to solidification cracking. In order for solidification cracking to occur three conditions must be satisfied during solidification. (1) The solidifying material must experience a tensile hydrostatic stress, (2) the material must be deforming plastically for voids to grow, (3) the ratio of the hydrostatic stress / effective stress must be sufficiently large for the voids to grow fast enough such that failure occurs before the material cools significantly below the local solidus temperature.
It was demonstrated that the temperature at which the pressure behind the weld pool becomes tensile increases with stiffer elastic constants, higher yield strength, increased power input, and for the disk specimen, distance from the weld start. It was observed that the magnitude of the triaxiality (pressure/effective stress) does not appear to significantly increase with location around the disk. The likelihood of cracking increases with distance from the weld in the disk specimen because the temperature at which the pressure behind the pool becomes tensile increases. The effect of this is that material more susceptible to cracking is loaded by the tensile pressure as the weld proceeds around the disk.

The thermomechanical conditions responsible for causing crack initiation on the outside edge of the weld fusion zone in the disk specimens were explained by noting that at the outer edges of the weld tensile pressures develop at higher temperatures than at the weld center. The outer edge cracks rather than the inner edge because the outer edge sees the tensile pressure earlier in time than the inner edge. Further, under the assumptions used in this work, the outermost elements under go plastic deformation over a larger temperature range than the center elements.

Finally, four disk tests were simulated and calculated crack initiation locations bounded those observed in the experiments. However, the observed centerline cracking was not predicted.

Future work will focus on including more information about the microstructure and better defining the mechanical properties near melt. Also of interest is extending the modeling techniques to capture alloy dependence of solidification cracking. Improvements in the model to predict the weld centerline cracks observed in the experiments is another goal.

\section{Acknowledgments}

The authors would like to acknowledge M. F. Horstemeyer for providing the constitutive model parameters and discussions regarding the damage model. The many weld experiments performed by J. Krafcik are also greatly appreciated. This work was funded by the U.S. Department of Energy under contract No. DE-AC0494AL85000.

\section{References}

1 Pumphrey, W. I., and Jennings, P. H.,. "A Consideration of the Nature of Brittleness at Temperatures above the Solidus in Castings and Welds in Aluminum Alloys". Journal of Institute of Metals 75. 235-256, 1948.

2 Singer, A. R. E. and Jennings, P. H., "Hot-shortness of the Aluminum-Silicon Alloys of Commercial Purity". Journal of Institute of Metals 73: 197-212, 1947.

3 Lees, D. C. G., "The Hot-tearing Tendencies of Aluminum Casting Alloys". Journal of Institute of Metals 72: 343-364, 1946.

4 Feng, Z., "A Methodology for Quantifying the Thermal and Mechanical Conditions for Weld Solidification Cracking”, Ph.D. Dissertation, Ohio State University, 1993. 
5 Brooks, J. A., Dike, J. J., and Krafcik, J. S., "On Modeling Weld Solidification Cracking”, Proc. Modeling and Control of Joining Processes, Orlando, FL, Dec. 1993, ed. T. Zacharia, AWS, 174-185, (1994).

6 Feng, Z., and Tsai, C. L., "Modeling the Thermomechanical Conditions at Weld Pool", Proc. Modeling and Control of Joining Processes, Orlando, FL, Dec. 1993, ed. T. Zacharia, AWS, 525-532, 1994.

7 Zacharia, T., and Aramayo, G. A., "Modeling of Thermal Stresses in Welds", Proc. Modeling and Control of Joining Processes, Orlando, FL, Dec. 1993, ed. T. Zacharia, AWS, 533-540, 1994.

8 Dike, J. J., Brooks, J. A., and Krafcik, J. S., "Finite Element Modeling and Verification of Thermal-Mechanical Behavior in the Weld Pool Region", Proc. 4th International Conference on Trends in Welding Research, Gatlinburg, TN, June, 1995, Ed. H. B. Smartt, J. A. Johnson, S. A. David, 159-164.

9 Feng, Z., Zacharia, T., and David, S. A., "Modeling of Thermomechanical Conditions in the Sigmajig Weldability Test", Proc. 4th International Conference on Trends in Welding Research, Gatlinburg, TN, June, 1995, Ed. H. B. Smartt, J. A. Johnson, S. A. David, 621-626.

10 Goodwin, G. M., "Hot Cracking: Measurement, Mechanisms and Modeling: Welding Journal 69 (2): 26-31.

11 ASM Handbook, Welding, Brazing, and Soldering, Vol. 6, ASM International, pp. 606-608, 1993.

12 Goodwin, G. M., "Development of a New Hot-Cracking Test - Sigmajig", Welding Journal 66(1): 33s - 38s, 1987.

13 Kutz, W. and Fisher, D. J., Fundamentals of Solidification, Trans Tech Publications, Switzerland, 1989.

14 Biffle, J. H., "JAC3D - A Three-Dimensional Finite Element Computer Program for the Nonlinear Quasistatic Response of Solids with the Conjugate Gradient Method", Sandia Report SAND87-1305, Albuquerque, NM, 1993.

15 Desai, P. D., Gilp, B. F., Cooney, J. S., and Bogaard, R. H., "Thermophysical and Mechanical Properties of 6061-T6 and 6061-O Aluminum Alloy from Room Temperature to Melt", MIAC Special Report 7, Center for Information and Numerical Data Analysis and Synthesis, Purdue University, West Lafayette, IN, March, 1995.

16 Kanouff, M. P., "'"The Effective Thermal Conductivity in Weld Pools", Internal Sandia Memo, April, 1994.

17 Goldak, J., Chakravarti, A., and Bibby, M. "A New Finite Element Model for Welding Heat Sources", Met. Trans. B, 15B, pp. 299-305, 1984.

18 Bammann, D. J., "An Internal State Variable Model of Viscoplasticity" in Media with Microstructures and Wave Propagation, Afiantis, E. and Davison, L. eds., Int. J. Eng. Sci., Vol. 8-10, Pergamon Press, p. 1041, 1984.

19 Bammann, D. J., Johnson, G. C., and Chiesa, M. L., “A Strain Rate Dependent Flow Surface Model of Plasticity", SAND90-8227, 1990.

20 Bammnn, D. J., Chiesa, M. L., Horstemeyer, M. F., and Weingarten, L., "Prediction of Ductile Failure in Metal Structures", in Failure Criteria and Analysis in Dynamic Response, Lindberg, H. E. ed., ASME, 1990.
21 Bammann, D. J., Chiesa, M. L., and Johnson, G. C., "Modeling Large Deformation and Failure in Manufacturing Processes", to appear in ICTAM 96 conference proceedings, Kyoto, Japan, Aug. 1996.

22 Lathrop, J. F., "BFIT - A Program to Analyze and Fit the BCJ Model Parameters to Experimental Data - Tutorial and User's Guide", Sandia Report SAND97-8281, Sandia National Laboratories, CA, December 1996.

23 Mosher, D., "Elevated Temperature Notched Tensile Testing of 6061 Aluminum for FY96 DPTB Damage and Failure, Case \#7164.230", Internal Memo, Sandia National Laboratories, Livermore, CA, Oct. 1996.

24 Tallon, J. L., and Wolfenden, A., "Temperature Dependence of the Elastic Constants of Aluminum", J. Phys. Chem. Solids, Vol. 40, pp. 831-837, 1979.

25 Cocks, C. F., and Ashby, M. G., "Intergranular Fracture During Power Law Creep Under Multiaxial Stresses", Metal Science, Aug-Sept, pp. 395-402, 1980.

26 Forest, B., and Bercovici, S., "Experimental Study of Mechanical Properties of Aluminum Alloys during Controlled Solidification: Application to Hot Tearing", Solidification Technology in the Foundry and Cast House, Coventry, Great Britain, Sept, pp. 607-612, 1980.

27 Matsuda, F., Nakagawa, H., and Sorado, K., "Dynamic Observation of Solidification and Solidification Cracking during Welding with Optical Microscope (I) - Solidification Front and Behavior of Cracking", Trans. JWRI, 11 (2), 67-77, 1982.

28 Nedreberg, M. L., "Thermal Stress and Hot Tearing during the DC Casting of Al-Mg-Si Billets", Ph.D. Dissertation, University of Oslo, 1991.

29 Zacharia, T., "Dynamic Stresses in Weld Metal Hot Cracking", Welding Journal Research Supplement, July 1994, 164s-172s.

30 Borland, J. C., "Generalized Theory of Super-solidus Cracking in Welds (and Castings)", 1960, British Welding Journal, Aug., 508-512.

31 Matsuda, F., Nakagawa, H., Nakata, K., Kohmoto, H., and Honda, Y., "Quantitative Evaluation of Solidification Brittleness of Weld Metal during Solidification by Means of In-Situ Observation and Measurement (Report I) - Development of the MISO Technique", 1983, Trans. of JWRI, 12 (1), 65-72.

32 Arata, Y., Matsuda, F., Nakata, K., Shinozaki, K., "Solidification Crack Susceptibility of Aluminum Alloy Weld Metals (Report II) - Effect of Straining Rate on Cracking Threshold in Weld Metal during Solidification", 1977, Trans. of JWRI, 6 (1), 91-104.

33 Clyne, T. W., Davies, G. J., and Eng, B., "A Quantitative Solidification Cracking Test for Castings and an Evaluation of Cracking in Aluminum-Magnesium Alloys", Brit. Found., 68, 1975, p. 238.

34 Katgerman, L., "A Mathematical Model for Hot Cracking of Aluminum Alloys During DC Casting", Journal of Metals, Feb. 1982.

35 Blanford, M. L., "JAS3D - A Multi-Strategy Iterative Code for Solid Mechanics Analysis, User's Instructions, Release 1.4, Internal Sandia Document, December, 1996. 